\title{
MINIMIZING GREENHOUSE GAS EMISSIONS FROM SHIPS USING A PARETO MULTI-OBJECTIVE OPTIMIZATION APPROACH
}

\author{
Zygfryd Domachowski \\ Gdańsk University of Technology, Poland \\ * Corresponding author: domachow@pg.edu.pl (Z.Domachowski)
}

\begin{abstract}
To confront climate change, decarbonization strategies must change the global economy. According to statements made as part of the European Green Deal, maritime transport should also become drastically less polluting. As a result, the price of transport must reflect the impact it has on the environment and on health.

In such a framework, the purpose of this paper is to suggest a novel method for minimizing emissions from ships, based on so-called Pareto multi-objective optimization. For a given voyage by a ship, the problem is to minimize emissions on the one hand and minimize fuel consumption or passage time on the other. Minimizing emissions is considered as the preferred objective. Therefore, the objective of minimizing fuel consumption or passage time needs to be reformulated as a constraint. Solving such a problem consists of finding most favourable path and speed for the ship and satisfying the optimization criteria.

Relatively new systems such as hybrid diesel-electric systems have the potential to offer significant emissions benefits. A hybrid power supply utilizes the maximum efficiency of the direct mechanical drive and the flexibility of a combination of combustion power from the prime mover and stored power from energy storage from an electrical supply, at part load and overload.

A new report by the American Bureau of Shipping suggests that maritime transport is likely to meet the International Maritime Organization's target by 2030, solely by using current technology and operational measures. However, this would not be enough to attain the target of reducing CO2 emissions by 2050 by at least 50\% compared to 2008. New technologies and operational methods must be applied.
\end{abstract}

Keywords: Minimizing emissions from ships; Pareto multi-objective optimization; Minimizing emissions as preference objective; Ship routing optimization; Hybrid power to lower emissions

\section{INTRODUCTION}

Reducing emissions of the greenhouse gases that cause global warming should be humanity's first reaction to the threat of human-caused climate change. It is necessary for humanity to be forward-looking to take responsibility for managing the climate. This can be viewed as the responsibility to ensure that conditions are created in which life can flourish.

In such a view, the decarbonization of the global economy is commonly discussed all over the world. However, on the one hand carbon dioxide is not the only greenhouse gas. On the other hand, there are other pollutants (such as heavy metals, nitrogen and sulphur oxides and coal ash) produced during the energy production cycle that have an impact on the environment. In many ways these are the more tangible and immediate concerns for the public. This is not the only problem, but unfortunately it is the main one.

Mitigating carbon dioxide emissions does not solve all the detrimental effects of energy production on public health and the environment.

The COVID-19 pandemic has derailed the global economy. Even if mitigation efforts are ramped up soon, they may be insufficient to prevent dangerous impacts. Therefore, society may be tempted to try to control the climate directly. This may be done only if individual states, industries and corporations are making attempts to curb the harm, recognizing past 
harms and changing everything. As some have argued [1], COVID-19 has presented society with an opportunity to respond to climate change through 'planned degrowth' that prioritizes the well-being of people over profit margins.

The Paris Convention requires a significant reduction in $\mathrm{CO}_{2}$ emissions to avoid global warming above $2^{\circ} \mathrm{C}$. However, if no measures are taken, $\mathrm{CO}_{2}$ emissions are projected to increase by between $50 \%$ and $250 \%$ by 2050 [2].

According to the European Green Deal Communication [3], transport should become drastically less polluting. Among other measures, the European Commission will take action in relation to maritime transport. The regulations should aim to accelerate the deployment of low-emission or zero-emission vessels [3]. The European Green Deal Communication also states that the price of transport must reflect the impact it has on the environment and on health. The European Commission will look closely at current tax exemptions, including those for maritime fuels. Moreover, the Commission will propose the extension of the European emissions trading system to the maritime sector. This will be coordinated with action on a global level, notably through the International Maritime Organization [4].

\section{PERFORMANCE CRITERIA FOR DESIGN AND OPERATION OF SHIPS' POWER PLANTS}

The operating profile of ships is diverse. In spite of such diverse operating profiles, a ship's power plant has to satisfy many performance criteria, including those relating to:

1. ship safety;

2. propulsion availability;

3. manoeuvrability;

4. fuel consumption;

5. pollutant emissions;

6. comfort arising from minimal noise, temperature, vibration and smell;

7. maintenance cost; and

8. purchase cost.

From the point of view of a ship's operation, the first six criteria should be considered. The criterion of a vessel's safety prevails over all other criteria for any operation. Furthermore, the propulsion availability and manoeuvrability criteria must be satisfied to make the ship's operation possible. It should be a matter of interest that criteria relating to fuel consumption, pollutant emissions, discomfort arising from noise, vibration and smell, and maybe maintenance cost are minimized.

The aim of ship control strategies in international shipping is to reduce fuel consumption and emissions. The role of the ship's control system is to adapt the ship's power and propulsion for a specific operation. At the same time, emissions should be limited according to the International Maritime Organization regulations. Since 1997, when Annex VI to the Marpol Convention was first adopted, more and more stringent changes have limited emissions from ships.

In regard to sustaining shipping in the short term, the ambition is to reduce total greenhouse gas emissions by at least $50 \%$ by 2050 compared to 2008 [4]. Among other measures, a reduction of ships' speed is discussed as a candidate [5].

On the one hand, the profit should be maximized by minimizing fuel consumption. On the other hand, environmental emissions should be minimized. Complying with the criterion of minimizing power production costs with merely legal constraints can make matters worse from the climate change point of view. Like most other industries, shipping prioritizes profit margins in the short term over the well-being of people. Ultimately, some of the dangerous impacts of greenhouse gases would be catastrophic for the future of the planet.

The fact of the matter is that minimizing greenhouse gas emissions and fuel consumption, and maybe discomfort arising from noise, vibration, and smell, is a set of goals representing an example of Pareto multi-objective optimization. Finding a solution to such a problem on which decision makers can agree is a topic in Multiple Criteria Decision Analysis.

\section{PARETO MULTI-OBJECTIVE APPROACH TO MINIMIZING GREENHOUSE GAS EMISSIONS FROM SHIPS}

A multi-objective optimization problem is given, for example, by the following problem statement [6]:

minimize $f_{1}(x), \ldots$, minimize $f_{m}(x)$

in which $\mathrm{f}_{1}(\mathrm{x}), \ldots, \mathrm{f}_{\mathrm{m}}(\mathrm{x})$ are called the objective functions, $\mathrm{x} \in \mathrm{X}$, and $\mathrm{X}$ is called the decision space. This definition does not explicitly state any constraint functions. In practice, such functions have to be incorporated. In general, $m>1$, but in practice $m \leq 3$, and usually $m=2$. Then the goal is: $\min f_{1}(x)$, $\min \mathrm{f}_{2}(\mathrm{x})$.

Let us consider an industrial process in which, on the one hand, profit should be maximized and, on the other hand, environmental emissions should be minimized. Solving such a problem is an example of multi-objective optimization. The so-called Pareto-optimal solution refers to a solution for which there is no way of improving any one objective without degrading at least one other objective. A situation is called Pareto-optimal if no change would lead to improved satisfaction for all the objectives.

The Pareto front is the set of choices that are Paretooptimal. The decision maker can make trade-offs within this set. Finding the Pareto front is particularly useful in engineering. It is conventionally shown graphically, which is possible for $\mathrm{m}=2$ and sometimes for $\mathrm{m}=3$.

Without additional subjective preference information, all Pareto-optimal solutions are considered equally good. The goal may be to find a representative set of Pareto-optimal solutions, or to find a single solution that satisfies the subjective preferences of a human decision maker.

In the shipping industry, a Pareto multi-objective optimization problem is to minimize the greenhouse gas 
emissions from a ship and minimize its fuel consumption. The last objective represents the maximization of profit.

\section{MINIMIZING GREENHOUSE GAS EMISSIONS FROM SHIPS}

In the nineteenth century steam engines were introduced for the mechanical propulsion of ships. Driving engines developed from reciprocal steam engines and steam turbines to diesel engines and gas turbines. Nowadays, most ships use diesel engines because of their high efficiency. Moreover, mechanical propulsion is particularly efficient at the design point (between $80 \%$ and $100 \%$ of the rated speed). This is the most efficient working point of a diesel engine. It is the point of minimum fuel consumption and, for the same reason, of minimum emissions.

In addition, mechanical propulsion consists of only three power conversion stages: the main engine, the gearbox and the propeller. This leads to low conversion losses. Therefore, mechanical propulsion is mostly used for transport ships such as tankers. For such ships, over $80 \%$ of the energy is converted in the main diesel engine. Thus fuel consumption, and by the same count emissions, can best be reduced by recovering the waste heat in the exhaust gas and cooling water to generate auxiliary electrical power and heat [7].

Mechanical propulsion remains the preferred method for ships that sail at a single cruise speed most of the time, because its fuel efficiency at full load is high. Cargo ships are ships of this type.

Consider an engine that operates close to the optimal working point from a fuel consumption point of view. However, when sailing in heavy weather or under other propulsion load, disturbances can provoke an overloading of the engine. Such an off-design condition represents an increase in fuel consumption and emissions. Providing a margin of load between the propeller load and the engine load from, for example, a battery or super capacitor can reduce the increase in fuel consumption and emissions. This additional electrical power might be generated from renewable energy sources.

This is an example of hybrid propulsion, using a combination of mechanical and electrical propulsion. Hybrid propulsion can benefit from the advantages of both. In the type of hybrid power supply discussed, the mechanical part consists of the supply of combustion power from a diesel engine, gas turbine or steam turbine. The electrical part is represented by the supply of stored power from an energy storage system such as a battery or super capacitor.

Several other ship types with mechanical propulsion operate at low power in certain operating modes [7]. For example, during transit tugs (over $50 \%$ of tugs operating around the globe use mechanical propulsion) only require $20 \%$ of the maximum power they require for towing. Offshore vessels perform numerous tasks, such as transit and dynamic positioning operations; naval ships perform traditional patrol operations in open sea as well as being deployed in littoral operations. Unfortunately mechanical propulsion has low fuel efficiency and produces high emissions at speeds below $70 \%$ of top speed. In particular, engine fuel consumption increases significantly at below $50 \%$ of the rated power. For these ship types, mechanical propulsion leads to high specific fuel consumption and high emissions.

Energy storage can provide the required electrical power and enables one or more engines to be switched off when they would be running inefficiently at part or no load. This can even enable the ship to sail temporarily without emissions. The energy storage can then be recharged when the engine is running at an operating point when less power is required. In such a situation, the specific fuel consumption and emissions are low.

Hybrid propulsion with a hybrid power supply utilizes the maximum efficiency of the direct mechanical drive and the flexibility of a combination of combustion power from the prime movers and stored power from energy storage from an electrical supply.

Batteries have only recently been used in maritime applications, but their popularity is growing very quickly.

\section{SHIP ROUTING OPTIMIZATION TO PLAN THE MOST FUEL-EFFICIENT PASSAGE}

All ocean-going ships are required to operate all year around in different circumstances. Any ship's routing must take into account conditions such as:

1. ocean currents;

2. ocean tides;

3. ship traffic volume;

4. land obstacles on shallow waters;

5. 'piracy threats' to be avoided; and

6. forecast weather conditions.

These factors are related to the movement of the ship. Keeping the crew, cargo, and the ship itself safe and secure is the primary goal. The most favourable paths and speed profiles then have to be investigated. Any choice of them affects the efficiency of the propulsion system in terms of fuel consumption and attainable passage time. For a given ship, its motion and propulsion efficiency are strictly related to the weather conditions through which it is navigating. Thus, the ship's route optimization requires a trustworthy forecast as well as an adequate mathematical model for the ship. The aim is to be able to assess the ship's behaviour in any given sea-state.

In general, there are three criteria to be optimized: safety, passage time, and fuel consumption. These define a multiobjective optimization problem. To solve this, the Pareto method has been adopted for several years. The goal is to find the Pareto-optimal set of routes for a given voyage of the ship [8]. The resulting Pareto-optimal set of routes enables the user (the human decision maker) to choose a trade-off between the optimization goals.

Over the years a large amount of research has been dedicated to methods that are generally referred to as weather 
routing. Their goal has been the development of reliable algorithms to search for the most favourable route, depending on the weather forecast. The urgent global need to reduce emissions has boosted research into advanced methods [9]. The aim is to enable strategies for the control of the ship, to improve the ship's operational efficiency.

\section{PRACTICAL APPLICATION OF PARETO MULTI-OBJECTIVE OPTIMIZATION TO MINIMIZING EMISSIONS FROM A SHIP}

For a given voyage of a ship, the aim is to solve the problem of minimizing the environmental emissions on the one hand and maximizing the profit on the other. This is a problem of multi-objective optimization, to which it is possible to apply the Pareto method. In the shipping industry, solving such a problem consists of finding the most favourable path and speed for the ship, satisfying the optimization criteria and constraints.

\section{OPTIMIZATION CRITERIA FOR THE GIVEN VOYAGE OF A SHIP}

The following particular criteria have to be taken into account:

1. maximizing safety; let us represent this as the relationship:

$\mathrm{f}_{\text {safety index }} \rightarrow \max$

2. minimizing emissions, represented as: $\mathrm{f}_{\text {emissions }} \rightarrow \mathrm{min}$,

3. minimizing fuel consumption, represented as: $\mathrm{f}_{\text {fuel consumption }} \rightarrow \mathrm{min}$

4. minimizing passage time, represented as: $\mathrm{f}_{\text {passage time }} \rightarrow \mathrm{min}$

5. maximizing profit, represented as: $\mathrm{f}_{\text {profit }} \rightarrow \max$.

The safety of the ship and cargo, as well as the comfort of the passengers and crew, are paramount constraints in any ship's routing. The decision maker must choose the safety criterion in preference to any other.

The so-called safety index may be defined as having normalized values in the range $0.0-1.0$. The value 1.0 means that the ship is hypothetically absolutely safe and the value 0.0 depicts a completely unstable situation.

Shipping is still largely weather-dependent, especially with regard to schedule, reliability, and control of emissions and fuel consumption. Actual hull stress and vertical or transverse accelerations influence the ship's safety and the comfort of crew. All such constraints may even determine the speed of the ship itself. Ultimately, the goal is to find a solution with which the decision maker can agree.

In a single-objective optimization, the optimal solution is usually clearly defined. However, in a multi-objective optimization the objectives can be conflicting. Therefore, instead of a single optimum, there is a set of trade-off solutions, generally called Pareto-optimal solutions. In this paper it is assumed that in the shipping industry the decision maker is asked to make a pairwise comparison of a set of Pareto-optimal solutions. In any such a pair, one objective is to minimize emissions, and the other is, in practice, to minimize fuel consumption or passage time.

Whenever fuel costs are a predominant component of operational costs, fuel consumption may be the second objective in a Pareto trade-off solution. However, when the freight rate prevails as a component of the operational costs, then passage time should be considered as such an objective in the Pareto trade-off solution.

\section{THE ROLE OF THE PARETO FRONT}

Let us take into account a so-called space of possible solutions, also known as the feasible decision space. These solutions are typically obtained using the values of the objective functions, or they may be the results of experiments. In the problem under consideration one of the axes represents the emissions function values, and the other the fuel consumption or the passage time function values. Denoting by $\mathrm{f}_{1}$ the emissions function $\left(\mathrm{f}_{1}=\mathrm{f}_{\text {emissions }}\right)$, and by $f_{2}$ the fuel consumption or passage time function $\left(f_{2}=f_{\text {fuel }}\right.$ or $\mathrm{f}_{\text {passage time }}$ ), it is possible to depict the so-called Pareto front, which is a set of trade-off solutions, generally known as Pareto-optimal solutions, see Fig. 1. These solutions are optimal in the sense that no other solutions are better than them when all the objectives are considered.

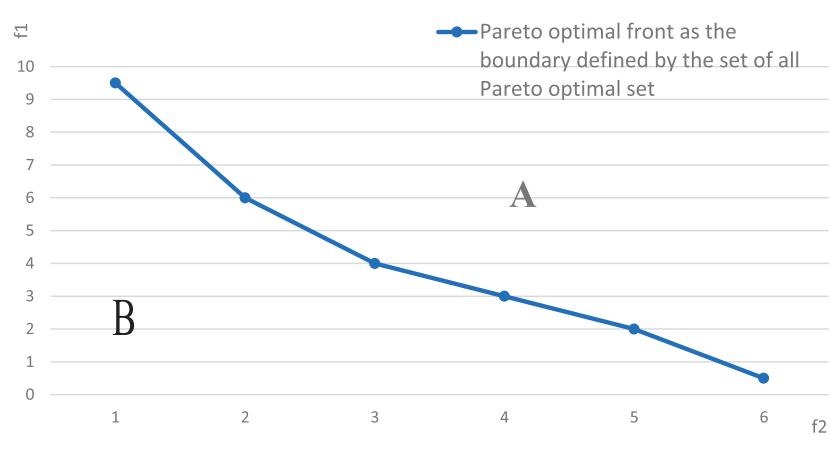

Fig.1 Graphical Depiction of Pareto-optimal Solutions
$\mathbf{A}$ - the solutions in this area are enclosed within the boundary of the decision space but are worse than the Pareto-optimal solutions
B - there are points that are better than the Pareto-optimal solutions, but they are outside the boundary of the decision space

The Pareto front enables the decision maker to choose a trade-off between the optimization goals. The Pareto-optimal solution refers to a situation around which there is no way 
of improving any objective without degrading at least one other objective. Without additional subjective preference information, all the Pareto-optimal solutions are considered equally good. In the situation under consideration this preference information results from the goal of minimizing the environmental emissions criterion. Therefore, the objective of the preference is minimal emissions. The other objective must then be reformulated as a constraint.

\section{CONSTRAINTS ON THE TRADE-OFF SOLUTIONS}

Generally, in practical applications, constraints have to be handled. When the fuel cost is predominant among the operational costs, then fuel consumption may be the objective that should be reformulated as a constraint. Then, for economic reasons, to satisfy a request for a minimum profit for the shipowner, the fuel consumption has to be limited.

Constraints on passage time may occur when, for example, shippers want their agricultural or perishable products shipped more quickly, or when there are scheduling or timetabling requirements for serving specific ports or meeting feeder connections [5].

A possible side effect of speed reduction, and of increasing the time for the same journey, may be that shippers are provoked to shift to other modes of transportation. If ships go more slowly, then shippers may be induced to choose road or railway alternatives, or even aircraft. This means, among other things, that a potential reduction in the ship's speed may also increase the overall greenhouse gas emissions.

\section{WEIGHTED SUM METHOD FOR SOLVING MULTI- OBJECTIVE OPTIMIZATION PROBLEM}

Several numerical algorithms for solving multi-objective optimization problems use the so-called weighted sum method, also known as the scalarization technique. Scalarization means that the objective functions are aggregated or reformulated as constraints. It is then possible to use single-objective numerical optimization methods to find different points on the Pareto front. A simple means to scalarize the problem is to attach non-negative weights to each objective function and then to minimize the weighted sum of the objective functions. Hence, the multi-objective optimization problem is reformulated as a linear scalarization problem. In the case considered above it takes the following form:

In this way a trade-off between the two objectives is given. It can be proved that, no matter which weights $\mathrm{w}_{1}, \mathrm{w}_{2}$ are chosen, the solution to the linear scalarization problem is

$$
\begin{gathered}
\operatorname{minimize} f(x)=\sum_{i=1} w_{i} \cdot f_{i}(x), \\
\text { where } x \in X, w_{i} \in[0,1], \sum_{i=1} w_{i}=1
\end{gathered}
$$

on the Pareto front [6].

\section{CONCLUSIONS}

It is enormously important to reduce the total annual greenhouse gas emissions from international shipping as soon as possible. According to a new report by the American Bureau of Shipping entitled Setting the Course to Low Carbon Shipping - Pathways to Sustainable Shipping and the comments on that report [10], the shipping industry is likely to meet the IMO's target of reducing $\mathrm{CO} 2$ emissions by at least $40 \%$ by 2030 , compared to the 2008 emissions, by using current technologies and operational measures.

In such circumstances a novel method of minimizing emissions from ships is suggested in this paper. It is based on so-called Pareto multi-objective optimization. A ship's operation is optimized to minimize its emissions with respect to unavoidable constraints determined by the human decision maker.

By 2050 international shipping will be dependent on fossil fuels for about $40 \%$ of its fuel requirements. On the basis of forecasts for energy consumption and trade, current technology alone will not be enough to reduce $\mathrm{CO}_{2}$ emissions by at least $50 \%$ by 2050 . New technologies and operational methods must be applied to find significant benefits related to the reduction of greenhouse gas emissions.

\section{REFERENCES}

1. J. Attali, 'Non à la decroissance, oui a une tout autre economie', Les Echos, 10 October 2019.

2. IPCC (Intergovernmental Panel on Climate Change), 'Special report on the impacts of global warming of $1.5^{\circ} \mathrm{C}$ '. https://www.ipcc.ch/sr15/download/ (access 28.02.2021).

3. EU, 'Communication on The European Green Deal', 11 December 2019. https://ec.europa.eu/info/publications/ communication-european-green-deal_en (access 28.02.2021).

4. IMC. International Convention for the Prevention of Pollution from Ships (MARPOL), Annex VI. http://library. arcticportal.org/1699/ (access 28.02.2021).

5. H.N. Psaraftis, 'Speed optimization vs speed reduction: The choice between speed limits and a bunker levy', Sustainability. 2019, 11, pp. 3-18.

6. M.T. Emmerich and A.H. Deutz, 'A tutorial on multiobjective optimization: Fundamentals and evolutionary methods', Natural Computing. 2018, 17, pp. 585-609.

7. R.D. Geertsma, R.R. Negenborn, K. Visser, and J.J. Hopman, 'Design and control of hybrid power and propulsion systems for smart ships: A review of developments', Applied Energy. 2017, 194, pp. 30-54. 
8. J. Szlapczynska, 'Multi-objective weather routing with customized criteria and constraints', The Journal of Navigation. 2015, 68(2), pp. 338-354.

9. M. Zyczkowski, J. Szlapczynska, R. Szlapczynski, 'Review of weather forecast services for ship routing', Polish Maritime Research. 2019, 4(104), pp. 80-89.

10. G. Plevrakis, 'Setting the course to low-carbon shipping', Maritime Reporter and Engineering News. June 2020.

\section{CONTACT WITH THE AUTHOR}

\section{Zygfryd Domachowski}

e-mail:domachow@pg.edu.pl

Gdańsk University of Technology

Narutowicza 11/12

80-233 Gdańsk

Poland 